\title{
Assessment of illiterate mothers' perceptions on birth control and the control measures practice in Zamfara State, Nigeria
}

\author{
Munirat Ajoke Abdulrahman * \\ Home Economics Department Federal College of Education (Technical), Gusau, Zamfara State, Nigeria.
}

Global Journal of Engineering and Technology Advances, 2021, 08(02), 062-067

Publication history: Received on 25 July 2021; revised on 26 August 2021; accepted on 28 August 2021

Article DOI: https://doi.org/10.30574/gjeta.2021.8.2.0125

\begin{abstract}
This study sought to assess the perceptions illiterate mothers on birth control and the control measures practice in Zamfara State using some selected Local Government Area (LGA) as case study. The descriptive survey research design was adopted. The study population consisted of all nursing but illiterate mothers in Zamfara State. Four hundred (400) illiterate mothers were selected sampled out of the study population using stratified simple random sampling technique. Two research questions and four null hypotheses were formulated and tested at the 0.05 levels of significance. The study made use of questionnaire as research instrument. The instrument was subjected to face and content validity by three (3) medical practitioners from Federal Medical Centre Gusau. The data collected from the study were analyzed using descriptive statistics (mean and Standard deviation) and the t-test statistical analysis was used to test the null hypotheses. Findings from the study revealed that there was a statistically significant difference between the Pre-test findings and the findings after being exposed to measures to be taken in birth control; There was a statistically significant difference between the Pre-test findings and the findings after being exposed to factors that contribute to their not utilizing some birth control measures and advised on the way forward.
\end{abstract}

Keywords: Perceptions; Illiterate Mothers; Birth Control; Control Measure Practices

\section{Introduction}

In Nigeria today, the concept of birth control has not been fully comprehended by its populace. According to Almuam (2007), family planning is defined as birth spacing and methods employed for preventing unwanted pregnancies or securing wanted pregnancies. [9] sees family planning as "the provision of birth prevention information services and appliances. It also involves teaching men and women about their bodies and teaching them how to prevent births usually with contraceptives but sometimes also with abortion or sterilization" (p.56). Family planning could further entail making decisions on the number of children; couples want to have by using different methods to achieve that, ranging from contraceptives to use of condoms, male and female sterilization among others.

There have been a lot of campaigns on the use of family planning and reduction of population from country to country especially in Nigeria. Even at that, a study by National Population Commission (2009) indicates that "contraceptive use is still low in many developing countries". This could be related to lack of adequate information and ignorance [1] [11] adds that, other factors such as "culture, low education, poverty and poor access to information on contraceptive are among numerous reasons that have been identified by scholars that militate against the use of family planning methods".

Traditional values also play a big role in family planning acceptance and decision, as many cultures and traditions support giving birth to as many children as possible. Some see it as a thing of pride. In places like "Jesse" Ethiope West

${ }^{*}$ Corresponding author: Munirat Ajoke Abdulrahman

Home Economics Department Federal College of Education (Technical), Gusau, Zamfara State, Nigeria. 
Local Government Area of Delta state, a man with many children is regarded as a strong and rich man, as such, family planning acceptance is very minimal. "Traditional values feature prominently because the cultural valuation of children is evident in studies which indicate that, among Nigerians, having fewer than five surviving children negatively affected the use of family planning methods" [1].

\section{Women Perception on Birth Control in Nigeria}

A study conducted among the Kanuris in Nigeria revealed that few Kanuri women used modern methods of family planning, the barriers being objection by their husbands, the fear of delayed return to fertility, damage to the reproductive apparatus and the belief that modern contraception was introduced to reduce Muslim populations [4]. This implies that most women do not want to go into family planning because of its effect such as delayed return to fertility, fear of damage caused to the womb or other parts in them that might prevent them from giving birth again.

Further examples, "the Suri people of Ethiopia prevent and delay pregnancies using natural family planning methods. The desired benefit is that women regain their strength following the injuries caused by pregnancy and delivery, and that attention can be given to the welfare of growing children. But these objectives are often countered by lack of access to modern family planning methods and the desire for many children within a socio demographic context of threats to their tribal survival" [3]. For example, [9] gives detailed analyses of peoples' perceptions on family planning in Benue state, Nigeria by having a comparative analysis and peoples' perspectives of health care facilities. He opines that: In spite of the introduction of family planning services as means of curbing fertility rate, the population still rises because of the attitudes of the people involved i.e. the African view of having many children with the notion "in case one dies the other will replace". He further noted that, the devaluation of female birth hinders family planning in that when a couple keeps giving birth to females, they tend to neglect family planning because they are looking for a male child.

\section{Statement of the problem}

Increase in population has caused many difficulties, especially in underdeveloped countries, because it has triggered limitation of resources along with a greater economic burden. In addition, the increased population has also resulted in water shortages along with insecurity of food and energy. High fertility has also increased the chances of health risks for mother and child, leading to poor quality of life, and reduces access to education, food, and employment [5].

Illiterate mother also encounters issues of having too many children. This problem has a profound effect on the maternal health. The mother doesn't get time to relax her body and provide sufficient physical and nutritional supplements needed to restore energy. Along with this, mothers also undergo some psychological disturbances like: depression, violent etc. that will not enable them to provide proper attention and nourishment to their children [12].

In Zamfara state, people seem not to consider the consequences of having large family, this has been attributed to the bearing of large number of children in the family and as a result, many children are relegated to street begging as almajirai. Majority of the women of child bearing age are illiterate or semi-illiterate and mostly petty traders/farmers, they are also ignorant of the fact that birth control does not mean that one should stop producing children, but that one should plan to control the birth naturally and artificially in order to produce only as many children as one can cater for.

\section{Objectives of the study}

The aim of the study is to assess the perceptions of illiterate mothers on the birth control and the control measures practice in Zamfara State - Nigeria. The specific objectives of the study were to;

- $\quad$ Determine the birth control measures practice by the illiterate mothers.

- Determine the factors that contribute to their not utilizing some birth control measures.

\subsection{Research Questions}

The following research questions guided the study:

- What are the types of birth control measures practice by the illiterate mothers in Zamfara State, Nigeria?

- What are the factors that contribute to their non-utilization of some birth control measures in Zamfara State? 


\subsection{Research Design}

A descriptive survey research design was adopted for the study to assess Perceptions of Birth Control and the Control Measures Practice by the Illiterate Mothers, In Zamfara State.

According to[12]. A survey research design is a study in which a sample is taken from a well-defined population which involves the collection of data in order to test hypothesis or answer research questions concerning the current status of the subject.

The geographical area covered by this study was Zamfara State, where four Local Government Areas were randomly selected across the three geographical zones of the state, namely: Gusau, Kaura Namoda, Talata Mafara, and Maradun LGAs.

The population for the study was made up of married illiterate women, nursing mothers and those who are expecting children across the state. The respondents were spread across three (3) zones in the state, where four local government areas were considered, and each had a total of one hundred respondents.

Sample sizes of 400 respondents were selected out of the entire population. One hundred (100) responds from each selected local government areas. The researchers intend to use the table of sample size, confidence level and confidence interval for sample adopted from [10]. At (95\% confidence level and \pm 3 confidence interval), as the conventional sampling strategy, the study intend to use 95 percent confidence level and 3 percent confidence interval [10]. A purposive sample technique was used in selecting the respondents, as it is the kind of sample where only the married women as well as nursing mothers were the targeted group [4].

The instrument used for data collection was a structured questionnaire containing 50 items. The items were based on the research questions formulated, which guided the study. The instrument was divided into two parts, Part A contained background information and part B contained other questions on the use of Birth Control in Zamfara State.

The instrument was subjected to face and content validity by three (3) experts who are specialists in the area of Health, medical doctors from FMC Gusau. Their observations were used to correct the instrument.

The category of respondents used during the pilot study was chosen from Tsafe local government and Bungudu LGAs for the reliability test, however these people were not part of the population for the main study. The internal consistency of the instrument will be determined by analyzing the data collected from the respondents using statistical package for social science (SPSS) version 2.0.

\section{Results}

\subsection{Research Question 1}

What are the types of birth control measures practice by the illiterate mothers in Zamfara State, Nigeria?

Table 1 Types of birth control measures practice by the illiterate mothers in Zamfara

\begin{tabular}{|c|c|c|c|}
\hline Test & No of Responded & Mean (x) & SD \\
\hline Pre-test & 400 & 0.3 & 0.5 \\
\hline Post-test & 400 & 3.66 & 0.65 \\
\hline
\end{tabular}

Table1 revealed the types of birth control measures practice by the illiterate mothers in Zamfara. Therefore, the table indicated that the pre-test finding was $(0.3)$ while the post-test was (3.66). The difference observed was further subjected to t-test analysis to find out if it is significant to draw conclusion.

\subsection{Research Question 2}

What are the factors that contribute to their non-utilization of some birth control measures in Zamfara State? 
Table 2 The factors that contribute to their non-utilization of some birth control measures in Zamfara

\begin{tabular}{|l|c|c|c|}
\hline Test & No of Responded & Mean (x) & SD \\
\hline Pre-test & 400 & 0.3 & 0.1 \\
\hline Post-test & 400 & 2.65 & 593 \\
\hline
\end{tabular}

Table 2 revealed the factors that contributed to the illiterate nursing mothers for their non-utilization of some birth control measures in Zamfara. The table revealed that the mean score of pre-test was 0.3 while that of post-test was 4.00 . The difference observed was further subjected to t-test analysis to find out if it is significant to draw conclusion

Ho1: There is no significant relationship between birth control and illiterate mothers' perceptions.

Table 3 Test analysis between the pre-test data and the relationship between birth control and illiterate mothers' perceptions

\begin{tabular}{|l|l|l|l|l|c|c|l|}
\hline Variable & No & Mean(X) & SD & Df & t-cal value & t-crit & Decision \\
\hline Pre-test performance & 400 & 0.3 & 0.05 & & & & \\
\cline { 1 - 7 } $\begin{array}{l}\text { Post-test } \\
\text { performance }\end{array}$ & 400 & 3.66 & 0.65 & 319 & 4.46 & 1.97 & Ho Rejected \\
\hline
\end{tabular}

As shown in Table 3. The t-cal value (4.46) was > than the t-crit (1.97) for 400 degree of freedom at 0.05 alpha level of significance. This indicates that the null hypotheses which stated that there is no significant relationship between birth control and illiterate mothers' perceptions. The pre-test is rejected. Therefore, the alternative hypotheses is upheld that means that there is positive significant difference between the pre-test performance of the relationship between birth control and illiterate mothers' perceptions. The findings of the study revealed that mother do better when exposed to the use of contraceptive for birth control.

Ho2: There is no significant relationship between birth control and the number of child birth

Table 4 t-test analysis between the relationship between birth control and the number of child birth

\begin{tabular}{|l|l|l|l|l|c|c|l|}
\hline Variable & No & Mean(X) & SD & Df & t-cal value & t-crit & Decision \\
\hline Pre-test performance & 400 & 0.3 & 0.1 & 319 & & & \\
\cline { 1 - 5 } $\begin{array}{l}\text { Post-test } \\
\text { performance }\end{array}$ & 400 & 4.00 & 2.65 & & 6.93 & 1.97 & Ho Rejected \\
\hline
\end{tabular}

As shown in Table 4, the calculated t-cal value (6.93) is > than the t-crit (1.97) for 400 degree of freedom at 0.05 alpha level of significance. This indicates that the null hypotheses which stated that there is no significant relationship between birth control and the number of child birth and the pre-test data, is rejected. Therefore, the alternative hypothesis is upheld that means that there is positive significant difference between the pre-test performances of the mothers. The findings of the study revealed that Mothers do better when exposed to method of birth control and the number of children. 


\section{Discussion}

Going by the analysis of the study, the findings revealed that:

- $\quad$ There was a statistically significant difference between the Pre-test findings and the findings after being exposed to measures to be taken in birth control;

- There was a statistically significant difference between the Pre-test findings and the findings after being exposed to factors that contribute to their not utilizing some birth control measures and advised on the way forward.

\section{Conclusion}

The findings on birth control and the control measures practice in Zamfara State Nigeria as perceived by illiterate mothers show quite clear that the major problems faced by mothers in this part of the world is lack of knowledge of the significance of birth control amongst illiterate mothers and even some educated ones. Birth control measure is important as it allows mothers to recover after birth and it gives them enough time to take care of their child before another conception. The measures also help them prepare their system and ready for another pregnancy which lead to a healthy childbirth and avoid any form of complications.

\section{Recommendations}

Further studies should examine perspectives of the health providers more thoroughly, and include the perspectives of NGO staff and religious leaders. These groups of participants can provide new perspectives and help us understand the concept of birth control even more holistically.

\section{Compliance with ethical standards}

\section{Acknowledgments}

The author sincerely appreciates the Tertiary Education Trust Fund (TETFUND) in Nigeria for the Institution Based Academic Research (IBR) merged - 2017/2019 through the Federal College of Education (Technical) Gusau.

\section{Statement of informed consent}

No informed consent from any individual that was included in the study.

\section{References}

[1] Adinma JIB, Nwosu BO. Family planning knowledge and practice among Nigerian women attending an antenatal clinic. Advance contraceptive. 2005;11(4): 335-344.

[2] Almuam YKA. Knowledge, attitude and practice towards modern family planning in Mukalla, Yemen. A Thesis submitted in partial fulfillment for the requirements of the degree of Master of Science (Family Health). Retrieved August 19th, 2011.

[3] Eyayou Y, Y Berhane, L Zerihun. Socio cultural factors in decisions related to fertility in remotely located communities: the case of the Suri ethnic group". Ethiop J Health Development. 2004;18(3): 171-174.

[4] Mairiga AG, AA Kullima, B Bako, MA Kolo. Socio cultural factors influencing Decision making related to fertility among the Kanuri tribe of north-eastern Nigeria". Afr. J. Prm. Health Care Fam. Med. 2010;2(1).

[5] Mbizvo MT, Phillips SJ. Family planning: Choices and challenges for developing countries. Best Pract Res ClinObstetGynaecol. 2014; 28:931-943.

[6] National Population Commission (NPC) Nigeria. National Demographic and Health Survey (NDHS). ( NPC, NDHS; 2015) Final report on fertility rates, contraceptive use and birth interval among Nigerians. Abuja, Nigeria.

[7] National Population Commission (NPC) Nigeria and ICF Macro. Nigeria demographic and health survey 2008. Abuja Nigeria": National Population Commission Abuja and ICF Macro USA. 2009.

[8] Nwosu UM, Eke RA,Chigbu LN.Factors Influencing the Practice of Modern Family Planning in Rural Communities of Abia State, Nigeria. ABSU Journal of Environment, Science and Technology. 2011;1: 128-136. 
[9] Onokerhoraye AG. Health and Family Planning Services in Nigeria: A Spatial Perspective. The Benin Social Sciences Series for Africa, University of Benin, Benin. 1997; 1-353.

[10] Rebecca S. Male Involvement in Family Planning Empowers Women. K4Health. 2011.

[11] Reshma MS. Awareness in women perception for family planning a case study of Baliyanavillag (Rohtak) International Journal of Multidisciplinary Research and Development. 2015;2(2): 161-163.

[12] Sonia S. The Effects of Education, Poverty, and Resources on Family Planning in Developing Countries. Clinics Mother Child. 2018.

[13] Sedgh G, Hussain R. Reasons for contraceptive Nonuse among women having unmet need for contraception in developing countries.2014. 